\title{
Hive minds: distributed intelligence within the biomimetic studio
}

\author{
S. Barry \\ Manchester School of Architecture, Manchester, UK
}

\begin{abstract}
Biomimetic design finds its muse in the natural world, more pertinently from the processes, anatomy, and function of site-specific flora and fauna. Maintaining a critical role in the development of a sustainable and environmentally responsible society, it relates to the dynamic between climate and living organisms, seeking to work with rather than against the external environment, promising to yield new means by which built environment research and design professionals may respond to and interact with their environment. At Manchester School of Architecture, innovation within biomimetic design studio culture has led to the incorporation of design strategies, which examine the properties of living systems in order to extrapolate desirable attributes from them and subsequently synthesise new responses. Employing research by design methodologies, students learn from the evolution of natural systems, incorporating these findings in their design work, emphasising ways of thinking and designing that brings architecture into a process of environmental and biological focus. As such, the methodology employed raises the prospect of closer integration of form and function, promising to yield new means by which students may respond to and interact with their own environment. This paper advocates the proposition and utilisation of the biomimetic model with regard to architectural education and building design. The development of which may prove more than a hypothetical metaphor, but a new biomimetic design paradigm, a model for holistic, sustainable urban design, an ecologically synergistic, generative architecture of an energy positive and progressive tomorrow.

Keywords: biomimetics, process-based ecotonic architecture, biomimetic sustainability, architectural education.
\end{abstract}




\section{Introduction}

The conceptual apparatus of architecture has always given a central role to the relationship between mankind and nature, the shapes of living organisms having been adapted for architectural use [1]. The material practice of architecture is at the beginning of a substantial reconfiguration in which the convergent fields of biology, structures, engineering and computation has ignited a previously unexplored evolutionary process. Natural systems provide a new conceptual model for biomimetic design experiments, exploring the architectural interrelationship between site specificity, organism, efficiency and community proposing biomimetic solutions to the future urban built environment.

Biomimetic design maintains a critical role in the development of a sustainable and environmentally responsible society. It relates to the dynamic between climate and living organisms, seeking to work with rather than against the external environment. It raises the prospect of a closer integration of form and function, promising to yield new means by which built environment research and design professionals may respond to and interact with their environment, and the design potential and responsibility of designing within it.

\subsection{The biomimetic model}

Biomimetic architecture concerns itself with climate (or perception of climate) as a major contextual generator, and with benign environments using minimal energy as its target. Drawing first inspiration from Gibson who describes ecology as a fit between niche and occupier [2], we reinterpret place through notions of ecology, evolution and environmental forces. This proposes an advancement from Norberg-Schultz's [3] theories of space, place, space and character, and environmental forces (climatic, social and perceptive) to complete the grammar of architecture. By applying process based natural analogy, mediation is achieved between the architecture of ecological time and times disembodiment, a by-product of the postmodern condition.

The M. Arch Atellier QED (qoud erat demonstrandum), at Manchester School of Architecture has developed its studio culture as a prototype pedagogical hive mind. Two holistic models of natural systems, organism and community are applied to architecture in order to determine the formation of an environmental ethic. To create an autonomous architecture it is necessary to have a model that is both ecologically and ethically sound; the single idea of an organism is not so. Here individual buildings must be seen as part of an archi-ecosystem, isolatory vacuums both natural and intellectual are biocidic.

\subsubsection{Biomimetic architecture at MSA}

Bioclimatic analysis and design delivers a built form that enables oscillations around and between a given set of environmental parameters: maintaining bioclimatic homeostasis. The exchange of climatic information and energy functions over time, displaying attributes of growth viewed by Thompson [4] to always be a 'function of time', so that growth and metamorphosis be considered 
as events in time and space. Strategic and tactical approaches regarding successful form and function are informed by a thorough understanding of appropriate site analysis. A climatically derived form simultaneously signs and interprets place whilst maintaining a gradated continuum between inside and out. Appropriate signing of place clearly acknowledges the already demonstrable effect the climate has upon it. For this purpose, building intelligence is both passive and reactive, mitigating the effects of a dynamic external environment upon internal conditions whilst harnessing their energy so as to maintain optimum internal environment.

Through this analysis biomimetic design challenges the notions of 'sustainability` and how contemporary ideologies may be translated into living systems with a future, rather than future living systems. Allowing the development of broad areas of research that promote holistic rather than exclusive architectural models for sustainable design, that merge an astute selection of observed properties with sophisticated artificial technologies and thus inform their subsequent hybrid development.

\subsubsection{Biomimetics: aesthetics versus process}

Recently, process based biomimetics; a concept closer in fidelity to the ecology of life has emerged generating a new architectural polemic within the QED research unit at MSA.

Bios, life is not an aesthetic, it is a process. Empty replication in architecture delivers a superficial pastiche of "the natural". Ultimately redundant, this artificial offspring of the ego is not the natural progeny of interpreting site or place. No amount of aesthetic camouflage will alter the fact that architectural interventions remain just that; they cannot be appropriated into an aesthetic chimera. Rather its form should interpret honestly the processes and circumstances in which it exists as a climatic modifier within its (urban) ecosystem.

The study of process in intrinsically context based, one cannot be studied without each other. The studio instead seeks to produce ecologists of built form; Archi-ecologists who through research demonstrate an understanding of the processes involved in nature, seeking to emulate how they work rather than simply how they look. Through understanding ecological processes we can extrapolate these into architectural situations.

\section{Hive mind: ecotonic autopoesis}

It is an autopoetic assumption that the boundaries of an organism are not defined according to physical boundaries such as skins but are extended along its sensory and functional inputs and outputs [5]. Architecturally inclusive and yet clearly linked to resource flows across the site and through the building. Systems constantly seek to actively distinguish themselves from their environment in an attempt to preserve their distinctness and maintain their identity. It is a complex landscape in which fragments may retain their identity and yet meld, through negotiation and chance, into a new form of continuity [6]. Boundary 
maintenance is a crucial part of the self-preservation of all systems, which can be understood as self-reverentially enclosed life-worlds populated respectively by friends and enemies. Such systems are latent with relevant potentials, both for threats to members of such systems, as well as for possible sources of 'energy' and 'nourishment' able to sustain and evolve new arrangements [7].

\subsection{Alpine cliff climber}

For example, symmetrical schismogenesis occurs when two or more conditions reinforce each other within given situation and encourage exponential growth in one direction [8], generating an architectural ecotone, tectonic intervention. Complementary schismogenesis occurs when 'mutually promoting' actions are essentially dissimilar but mutually appropriate [9]; a concept tested in Alpine Cliff Climber (Figure 1), which aims to provide a direct link between two Alpine resorts in one smooth flow creating a parasitic symbiosis. The tower is primarily a cliff scraper with the majority of the building mass climbing the great cliff heights of the fragmenting urban barrier.

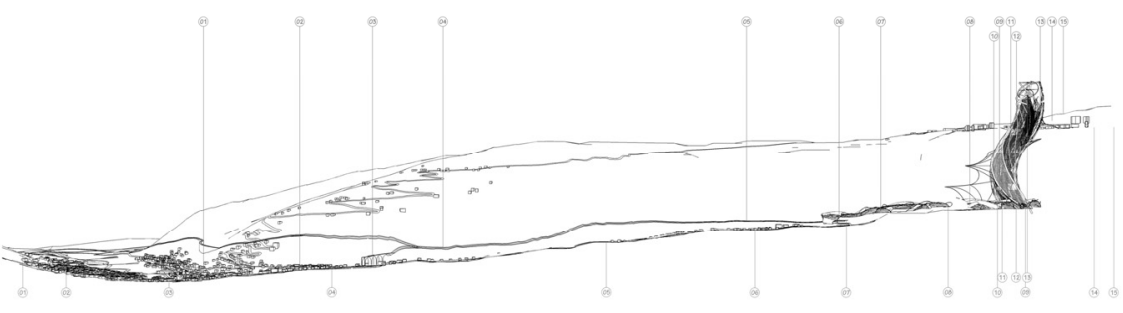

Figure 1: $\quad$ Alpine Cliff Climber, T. Bedford, MSA BArch.

Investigation into the growth patterns of climbing plants opened a basis for mimicry in regards to their helical formation and tendril growths used to scale vertical faces. The organic building shape evolved through light studies, creating the optimal shape to collect the maximum available solar gain for energy generation at the site. To take advantage of the location's wind conditions a single large helical turbine is integrated into the top of the tower to generate energy.

The bio construction combined with growth formation of climbing plants is what allows the climbing plant to minimise material usage and to maximise strength and growth height. The tower's internal and external structures mimic the natural helical formation creating maximum strength and stability within an organic shaped cliff scraper. Rock face ties mimicking natures tendrils, reach out from the tower's primary structural cores connecting them to existing natural cracks and faults within the cliff face using adapted rock climbing techniques. This combination allows the tower to freely twist and bend without compromising structural stability.

Ecotones have been described by Holland et al. [10] as 'zones of transition between adjacent ecological systems, having a set of characteristics uniquely 
defined by space and time scales and by the strength of interactions between adjacent ecological systems', as such they are dynamic entities with both a spatial and temporal property [11]. As such Alpine Cliff Climber creates the desired direct link to provide efficient movement between the two alpine resorts, whilst also providing an effective transition zone or ecotone (Figure 6), a dynamic intervention to an otherwise fragmenting urban barrier.

\subsection{ParaSITE/ecotone}

The study of process in intrinsically context based, one cannot be studied without each other. Process based biomimetics seeks to produce ecologists of built form; Archi-ecologists who through research demonstrate an understanding of the processes involved in nature, seeking to emulate how they work rather than simply how they look, challenging notions of environmental complexity, structural formation and habitation (Figure 2).
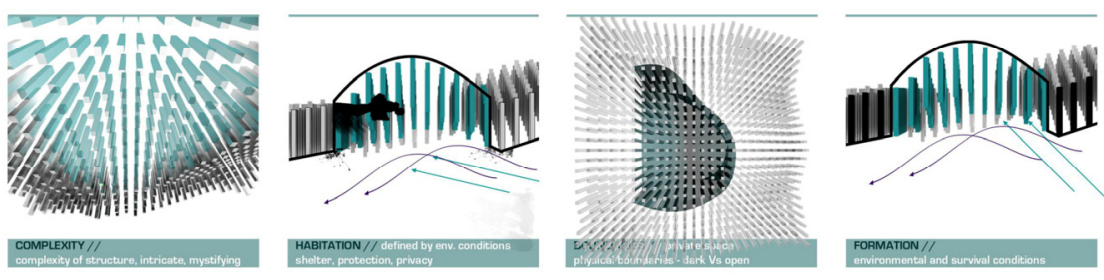

Figure 2: $\quad$ Urban cave/speleogenic skin, C. Loucaides MSA BArch.

Through understanding ecological processes we can extrapolate these into architectural situations. This concept has been explored through a 'parasitic' site analysis conducted on areas undergoing urban regeneration in Manchester.

ParaSITE extrapolates a viral analogy identifying areas in need of parasitic regeneration. The biomimetic approach to this project identified Manchester as a healthy organism with a well developed “circulatory” network system. Some parts of this organism are thriving and some are disintegrating or undergoing change. The suggestion is to introduce a beneficial parasitic urban remediation process that would catalyse this process of change according to the needs of these areas. Considering the social and cultural needs of this site, one of the parasites introduced was responsible for developing a three-dimensional mesh of networks, thus increasing circulation and furthering the growth of other parasites.

This project formed a complete amalgamation of both site research and environmental factors (Figure 3), forming a site-specific masterplan. The threedimensional mesh of networks generated through ParaSITE analysis defined where the spaces, paths, bridges, and access points would be located in the final development. The network is defined by extending the surrounding roads/paths on the site plan, the wind patterns, sun altitude and longitude at different times of day and season and water movement. 

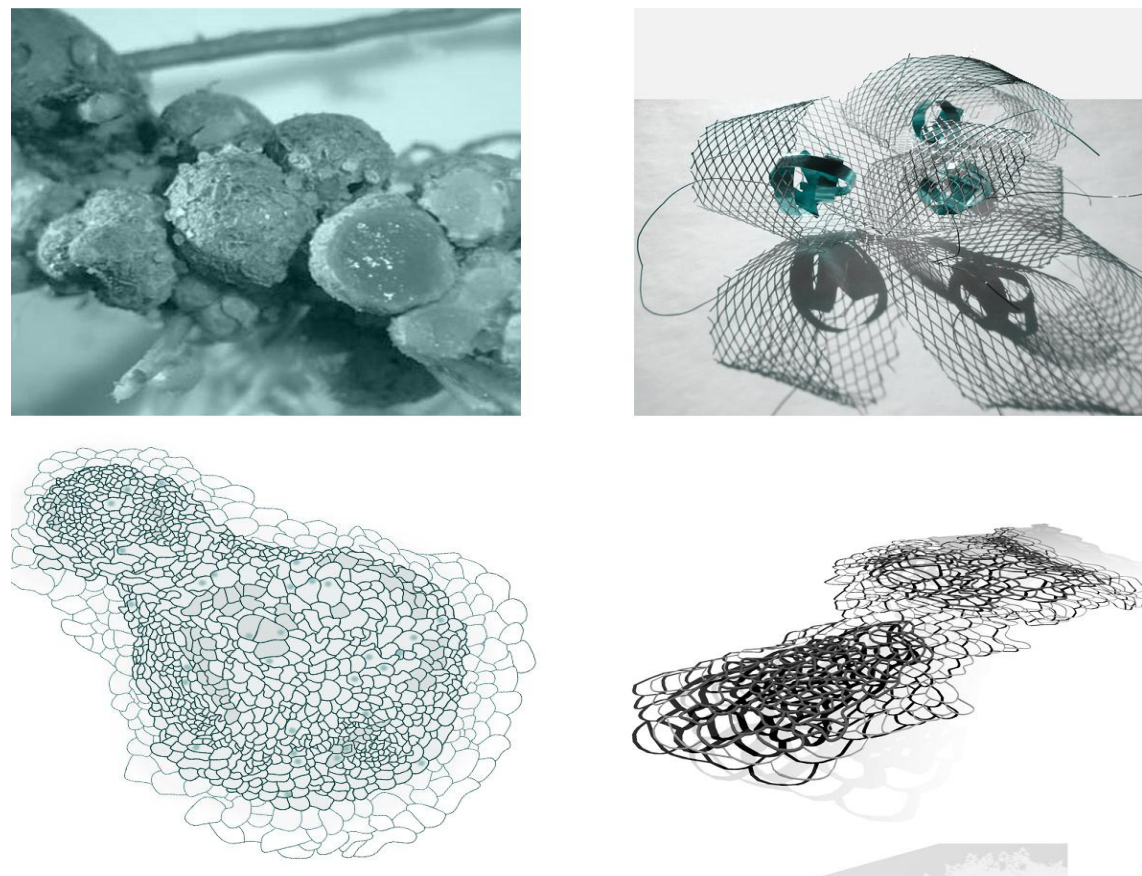

Figure 3: Development pattern of parasite characteristics; the parasite, conceptual form, growth/life pattern, architectural translation and architectural use. ParaSITE, Mayfield, Manchester, C. Loucaides MSA BArch.

Problems identified through the theoretical site research defined which life characteristics were required in order to overcome and solve them. Four parasitic organisms (living on or with a host for mutual benefit) were chosen. One of the parasites was responsible for de-composing/recycling, the other for fixing or controlling, the other for zoning and defining location of spaces, and finally the fourth for generating a "root" network system used for movement. Form and function of the spaces was a mixture of all the above characteristics; a traditionally biomimetic response, the way that nature would solve the problem. Whilst this remains a theoretical investigation, it has evolved to become a scalar ecotone; a zone of transition between adjacent ecological systems, having a set of characteristics uniquely defined by space and time scales and by the strength of the interactions between adjacent ecological systems.

\subsection{Ecotonal development}

Ecotones are edges [12], transitional areas [13] or boundaries [14-16] and are typically characterised in ecological research as areas displaying a high rate of change compared to that of adjacent areas [17]. This high rate of change is reflected in the ecotone dynamics and the fluxes between neighbouring 
ecological systems, affecting the structure at macro, meso and micro scales within these systems [18-20]. As such they occupy zones of transition, transformative spaces that are capable of adaptation and change.

As biological organisms we live our lives within spatio-temporal zones bounded by natural and artificial extensive boundaries; within zones extended by time and space, limited and marked by a borderline. However, there are latent zones which we also inhabit, ecotonic zones of intensity, for example those found in zones of temperature which define different ecosystems (from hot jungles to cold tundra). These zones are not bounded by spatio-temporal frontiers but by intensive borderlines, critical points of temperature, pressure, gravity, tension, density and connectivity. They are the points that define abrupt transitions in the state of the creatures, which inhabit those zones; and form the basis of the research into the potential ecotonal development and site remediation of the Siberian biomine.

\subsubsection{Siberian biomine}

The Siberian biomine (Figure 4) is concerned with exhibiting the plight of Norlisk, Siberia, one of the most polluted cities in the world, by demonstrating its inherent ecological similarities to Putorana, a UNESCO World Heritage Site of unquestionable natural beauty, and restoring the level of ecological health that equals its neighbour. The scheme is based upon complete remediation of the site, positively redeveloping its entire landscape ecology over a phased 200 year period. The current mining industry will be completely revolutionised through branding new sustainable and ecological mining processes; bioleaching. In time this will completely eradicate the existing mining methods employed by the metallurgy plants in Norilsk. Consequently, the interpretation centre becomes perpetually refreshed through different media over time, evolving technologically in sync with the changes of the landscape in which it sits.

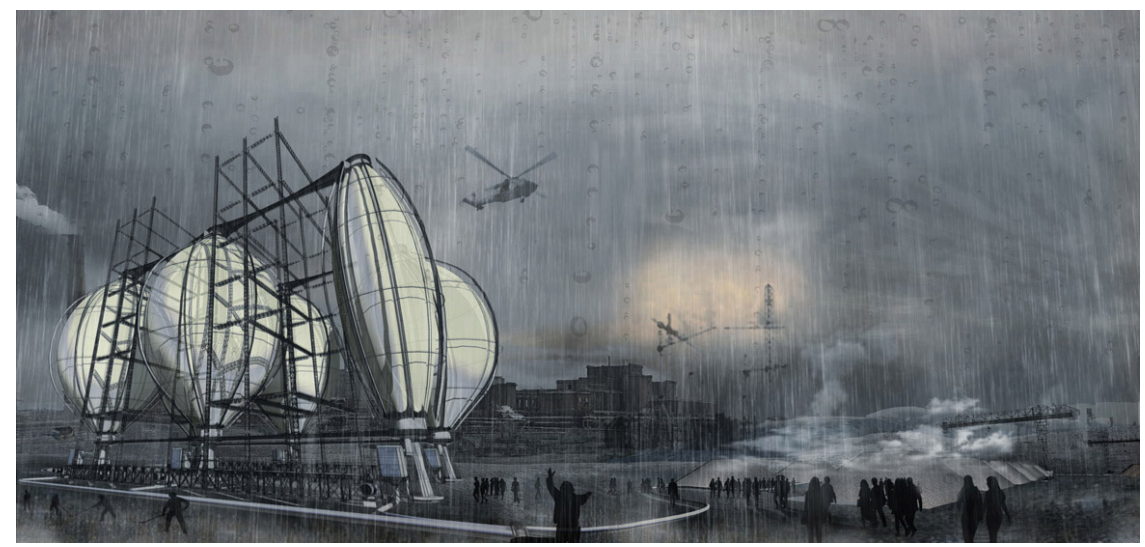

Figure 4: Siberian biomine, Norlisk, Siberia, R. Barker, L. Griggs, R. Vigelskas, J. Tan, MSA BArch. 
In the initial phase of the scheme visitors encounter a series of spaces designed to relate a comparative juxtaposition between Norilsk and the Putorana Plateau. As the industrial mining process gradually evolves and is replaced by the new bioleaching mining system, the visitor experience exhibits the changes to the entire city's infrastructure and habitat through an augmented reality within its exhibition suite.

\section{Conclusion}

The research by design case studies discussed in this paper demonstrate the possibilities of understanding natural processes and examining architecture through biological analogy. Para-biotic investigations conducted at Manchester School of Architecture propose that we should no longer regard buildings as truly living or as machines for living in, rather as a process based biotic architecture that supports life and living systems whilst exhibiting, but not possessing the attributes of life. The development and design of ecotonal and parasitic research may prove to be more than a hypothetical metaphor; instead they encompass the possibility of a new design paradigm, a model for holistic, sustainable urban design, an ecologically synergistic, generative architecture of an energy positive and progressive tomorrow.

\section{Acknowledgements}

The author wishes to acknowledge the following students whose BArch research projects are showcased in this paper: Robert Barker, Tom Bedford, Lindsay Griggs, Costas Loucaides, Reece Vigelskas and Jason Tan.

\section{References}

[1] Portoghesi, P., Nature and Architecture, trans. Young, Erika, Skira Editore, Milan, 2000.

[2] Gibson, J. J., The Ecological Approach to Visual Perception, Houghton Mifflin, Boston, 1979.

[3] Norberg-Schultz, C., Genius Loci - Towards a Phenomenology of Architecture, Rizzoli International Publications, New York, 1979.

[4] Thompson, D., On Growth and Form, Cambridge University Press, Cambridge, 1992.

[5] Hight, C., 'Subject boundaries negotiations - aka: getting' jiggy in da oikos', Steel, B., ed., Negotiate my boundary - mass customisation and responsive environments (+RAMTV), AA Publications, London, 2002, pp. 17.

[6] Woods, L., 'Inside the Borderline', “Borderline”, Research Institute for Experimental Architecture, Europa, Springer-Verlag, Vienna, 1998, pp. 32.

[7] Schumacher, P., 'autopoesis > definitions', AADRL design studio brief 01, Steele, B., ed., Negotiate my boundary - mass customisation and 
responsive environments (+RAMTV), AA Publications, London, 2002), pp. 20.

[8] Hight, C., Schumacher, P., 'Living prototypes for the autopoetic metropolis', AADRL design studio brief 03, Steele, B., ed., Negotiate my boundary - mass customisation and responsive environments (+RAMTV), AA Publications, London, 2002, p. 26.

[9] Bateson, G., "Steps to an Ecology of Mind: Collected Essays in Anthropology, Psychiatry, Evolution and Epistemology”, Chicago University Press, Chicago, 2000.

[10] Holland, M. M., Risser, P. G., Naiman, R. J., "Ecotones: the Role of Landscape Boundaries in the Management and Restoration of Changing Environments”, Chapman and Hall, New York, 1991, pp. 142.

[11] Hufkens, K., Ceulemans, R., Scheunders, P., 'Estimating the ecotone width in patchy ecotones using a sigmoid wave approach', "Ecological Informatics 3”, 2008, pp. 97.

[12] Orlóci, L., Orlóci, M., 'Edge detection in vegetation: Jornada revisited', “Journal of Vegetation Science 1”, 1990, pp. 311-324.

[13] Peters, D., Gosz, J., Pockman, W., Small, E., Parmenter, R., Collins, S., Muldavin, E., 'Integrating Path and Boundary Dynamics to Understand and Predict Biotic Transitions at Multiple Scales', "Landscape Ecology 21", 2006, pp. 19-33.

[14] Kent, M., Gill, W. J., Weaver, R. E., Armitage, R. P., 'Landscape and plant community boundaries in biogeography', "Progress in Physical Geography 21”, 1997, pp. 315-353.

[15] Fortin, M. J., Olsen, R. J., Iverson, L., Hunsaker, C., Edwards, G., Levine, D., Butera, K., Klemas, V., 'Issues related to the detection of boundaries', “Landscape Ecology 15”, (2000), pp. 453-466.

[16] Fagan, W. F., Fortin, M. J., Soykan, C., 'Integrating edge detection and dynamic modelling in the quantitative analysis of ecological boundaries', Bioscience 53, 2003, pp. 730- 738.

[17] Risser, P. G., 'The status of science examining ecotones', “Bioscience 45”, 1995, pp. 318-325.

[18] Naiman, R. J., Décamps, H., “The Ecology and Management of AquaticTerrestrial Ecotones”, Parthenon Publishing Group, Paris, 1990, pp. 316.

[19] Cadenasso, M. L., Pickett, S. T. A., Weathers, K. C., Jones, C. G., 'A framework for a theory of ecological boundaries', “Bioscience 53”, 2003, pp. 750-758.

[20] Saunders, S. C., Chen, J., Drummer, T. D., Crow, T. R., 'Modelling temperature gradients across edges over time in managed landscape', “Forest Ecology and Management 117”, 1999, pp. 17-31. 